\title{
STUDI PENERAPAN HACCP PADA PRODUSEN MI GLOSOR DI KOTA BOGOR
}

\section{STUDI PENERAPAN HACCP PADA PRODUSEN MI GLOSOR DI KOTA BOGOR}

\author{
A Jumiono1a, E Dihansih 1, I Rochmana ${ }^{1}$ \\ ${ }^{1}$ Magister Teknologi Pangan, Sekolah Pascasarjana, Universitas Djuanda Bogor, Jl. Tol Ciawi \\ No. 1, Kotak Pos 35 Ciawi, Bogor 16720. \\ a Korespondensi:Aji Jumiono, E-mail: dewiwahyuni@gmail.com \\ (Diterima: 19-04-2020; Ditelaah: 20-04-2020; Disetujui: 23- 04-2020 )
}

\begin{abstract}
This study aims to examine the application of HACCP in the glossy noodle (mi glosor) home industry in CV Taruna located in Bogor City by analyzing the stages of work activities in glossy noodle producers. Evaluation of the application of HACCP was carried out using standards recommended by the National Standards Agency (BSN) in 1999. This study began by analyzing the application of Good Processed Food Production Methods (CPPB) that were applied at CV Taruna. The application of CP Taruna CV Taruna is at level 4 which is the basic assessment in improving the application of HACCP in this small business. The next step is to analyze the flow diagram of the process of making glossy noodles and the determination of critical control points, critical limits, monitoring and preventive measures. There are 8 critical control points in the process of making glossy noodles. In the final stage, documentation and monitoring are made to control the implementation of the HACCP system that is run. The results of this study provide several recommendations for improving the application of HACCP in the process of producing glossy noodles at CV Taruna to improve its food safety application program.
\end{abstract}

Key Words : Bogor City, Glossy Noodles, SME's food safety, HACCP.

\begin{abstract}
ABSTRAK
Penelitian ini bertujuan untuk meneliti penerapan HACCP pada industri rumah tangga mi glosor di CV Taruna yang berlokasi di Kota Bogor dengan menganalisis tahapan aktivitas pekerjaan pada produsen mi glosor. Evaluasi penerapan HACCP dilakukan dengan menggunakan standar yang direkomendasikan dari Badan Standar Nasional (BSN) tahun 1999. Penelitian ini diawali dengan menganalisis penerapan Cara Produksi Pangan Olahan yang Baik (CPPB) yang diterapkan di CV Taruna. Penerapan CPPB CV Taruna berada pada level 4 yang menjadi penilaian dasar dalam perbaikan penerapan HACCP di usaha kecil ini. Tahap selanjutnya dengan menganalisis diagram alir proses pembuatan mi glosor dan penetapan titik kendali kritis, batas kritis, monitoring dan tindakan pencegahannya. Terdapat 8 titik kendali kritis pada proses pembuatan mi glosor. Pada tahap akhir dibuat dokumentasi dan monitoring untuk mengendalikan penerapan sistem HACCP yang dijalankan. Hasil penelitian ini memberikan beberapa rekomendasi dalam perbaikan penerapan HACCP pada proses produksi mi glosor di CV Taruna untuk memperbaiki program penerapan keamanan pangannya.
\end{abstract}

Kata Kunci : keamanan pangan, HACCP, mi glosor, Kota Bogor.

Jumiono. A., Dihansih. E., \& Rochmana. I. (2020).Studi Penerapan HACCP Pada Produsen Mi Glosor di Kota Bogor. Jurnal Pertanian, 11(1) 29-38. 


\section{PENDAHULUAN}

Mi glosor merupakan salah satu produk pangan khas di Kota Bogor yang biasanya sangat diminati terutama sebagai hidangan berbuka puasa di saat bulan Ramadhan. Mi glosor ini memiliki ciri berwarna kuning mengkilap dengan tekstur yang licin dengan bahan baku menggunakan tepung sagu aren. Disebut dengan istilah mi glosor untuk menggambarkan karakteristik mi ini yang mengalir lancar di kerongkongan saat dimakan.

Mi glosor diproduksi pada perusahaan dengan skala industri rumah tangga yang umumnya dilakukan dalam skala kecil, teknologi sederhana yang didapat secara turun temurun, serta sanitasi dan higiene yang umumnya masih kurang diperhatikan sehingga mutu dan daya tahan produk menjadi kurang baik menggunakan teknologi yang sederhana. Salah satu upaya yang dilakukan untuk peningkatan mutu dan keamanan produk yang dihasilkan adalah dengan penerapan cara produksi pangan olahan yang baik (CPPB) dan pencegahan bahaya yang dapat ditimbulkan dengan penerapan keamanan pangan yang mengacu pada penerapan Hazard Analysis and Critical Control Point (HACCP) dari Badan Standarisasi Nasional yang dikeluarkan pada tahun 1998. Penerapan keamanan pangan yang baik akan dapat menghindarkan dari bahaya yang mungkin timbul baik dari cemaran biologis, kimia, dan benda padat yang dapat mengganggu, merugikan, dan membahayakan kesehatan manusia.

Penerapan HACCP pada produksi mi glosor dilakukan dengan menerapkan suatu sistem yang dapat digunakan untuk menilai bahaya dalam suatu sistem produksi dan menetapkan sistem pengendaliannya untuk mencegah bahaya yang mungkin timbul. Maka dari itu, untuk meningkatkan keamanan pangan pada proses pembuatan Mie glosor ini diperlukan pengamatan dan penerapan HACCP. Pengamatan dan penerapan sistem HACCP ini diharapkan mampu mengidentifikasi, menganalisis serta mengendalikan bahaya yang mungkin terjadi pada proses pembuatan mi glosor.
Proses pembuatan mi glosor terdiri atas beberapa tahap, yaitu pembuatan biang (binder), pembentukan adonan, pencetakan, pemasakan, perendaman, dan penirisan (Purwani dan Harimurti, 2005). Pada tahap awal, sagu aren ditambahkan air dan pewarna makanan yang diaduk dan dipanaskan hingga membentuk gel dengan sempurna. Sagu kering ditambahkan ke dalam adonan pati yang berbentuk gel sambil terus diaduk hingga adonan kalis dan terbentuk adonan yang mudah ditangani. Selanjutnya adonan dicetak dengan cetakan mi yang ditempatkan di atas rak kawat. Setiap rak berisi satu lapis helaian mi, yang kemudian direbus dengan memasukkan mi ke dalam air mendidih sambil diaduk sampai mi mengapung kemudian diangkat. Mi yang telah diangkat ini kemudian dimasukkan ke dalam wadah berisi air dingin untuk mencuci mi dengan dua kali pencucian. Mi kemudian dibiarkan beberapa saat sebelum diangkat dan ditiriskan. Untuk mencegah mi lengket satu sama lain maka mi perlu dilumuri dengan minyak kacang secukupnya.

Salah satu standar keamanan pangan yang diakui adalah menggunakan Hazard Analysis and Critical Control Point (HACCP). HACCP ini merupakan suatu sistem yang digunakan untuk menilai bahaya dan menetapkan sistem pengendalian yang memfokuskan pada pencegahan. HACCP diterapkan pada seluruh mata rantai proses pengolahan produk pangan dengan melakukan program pengawasan, pengendalian, dan prosedur pengaturan yang dirancang untuk menjaga agar makanan tidak tercemar sebelum disajikan. Sistem ini merupakan pendekatan sistematis terhadap identifikasi, evaluasi pengawasan keamanan pangan secara bermakna (Disarikan dari Thaheer, 2005, Arisman 2009 dan Deswanti 2013).

Pendokumentasian penerapan HACCP di Indonesia menggunakan dua acuan dalam penerapannya, yaitu SNI 01-4852-1998 yang menjelaskan persyaratan industri pangan yang menerapkan HACCP dan Pedoman BSN 1004:2002 yang menjelaskan tentang rencana HACCP. Penerapan HACCP dalam proses produksi harus disertai dengan 
dokumentasi penerapan HACCP yang efekti dan efisien. Dokumentasi memiliki peran penting yang menjadi acuan dalam penerapan, pemeliharaan, dan pengembangan sistem HACCP untuk menjaga dan menjamin keamanan produk yang dihasilkan. Langkah-langkah penerapan HACCP sesuai pedoman BSN No. 1004-1999 meliputi : 1) menganalisis bahaya dan pencegahannya; 2) mengidentifikasi CCP dalam proses; 3) menetapkan batas kritis untuk setiap CCP; 4) menetapkan cara pemantauan CCP; 5) menetapkan tindakan koreksi; 6) menyusun prosedur verifikasi, dan 7) menerapkan prosedur pencatatan atau dokumentasi. Gambaran alur penerapan HACPP di CV Taruna digambarkan pada Gambar 1.

\section{MATERIALS AND METHODS}

Objek penelitian ini adalah CV. Taruna yang merupakan industri kecil yang memproduksi mi glosor yang berlokasi di Jl. Pancasan Baru No. 43, RT 01 RW 12, Desa Pasir Jaya, Kecamatan Bogor Barat - Kota Bogor. Penelitian ini dilaksanakan mulai Desember 2018 sampai dengan Maret 2019. Penelitian ini menggunakan metode deskriptif dengan meneliti analisis pekerjaan dan aktivitas pada suatu objek. Pengumpulan Data diperoleh dengan Studi literatur, wawancara dan observasi lapangan.

Gambar 1. Tahapan penerapan HACCP di CV Taruna Bogor.

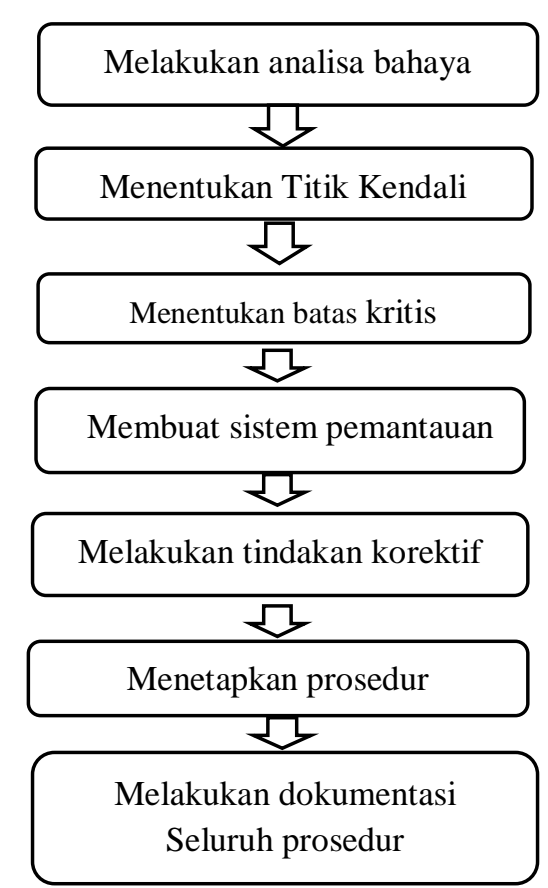

\section{Pengolahan Data}

Data penelitian diolah dengan tahapan : 1) penilaian kelayakan persyaratan dasar berupa penerapan Cara Produksi Pangan Olahan yang Baik (CPPB, 2) Perancangan Sistem HACCP di produsen mi glosor, dan 3) perancangan dokumentasi HACCP di produsen mi glosor CV Taruna - Bogor. Gambaran tahapan pengolahan data di CV Taruna Bogor digambarkan pada Gambar 1 berikut ini.

Gambar 2. Tahapan Pengolahan data di CV Taruna Bogor.

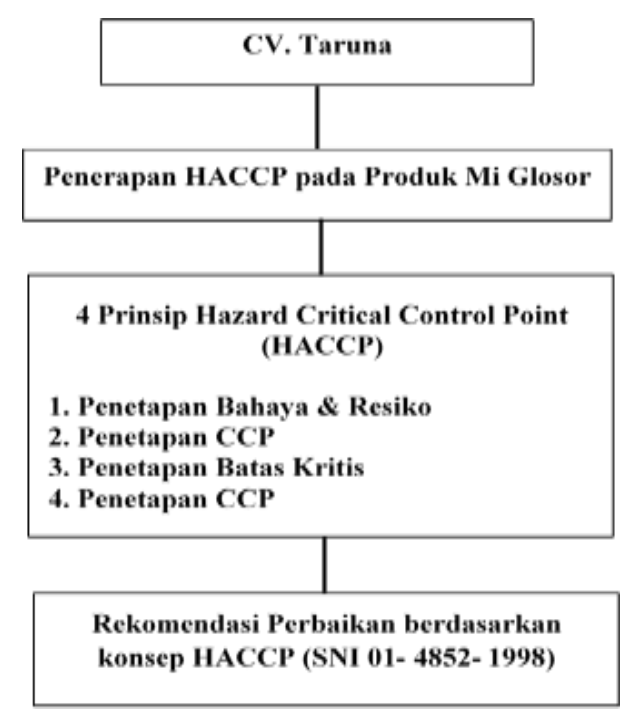

HASIL DAN PEMBAHASAN

\section{Penilaian Penerapan CPPB di CV Taruna Bogor}

Penerapan Cara Produksi Pangan Olahan yang Baik (CPPB) merupakan prasyarat (prerequisite) dalam penerapan sistem HACCP. Penilaian penerapan CPPB di CV. Taruna ini dilakukan dengan membandingkannya dengan Peraturan Kepala BPOM RI No. HK. 03.123.04.12.2206 Tahun 2012 tentang CPPB di Industri Rumah Tangga.

Pada Persyaratan CPPB-IRT sesuai aturan Kepala BPOM, penilaian kesesuaian terdiri atas 4 (empat) tingkatan, yaitu "harus" (shall), "seharusnya" (should), "sebaiknya" (may) dan "dapat" (can), yang diberlakukan terhadap semua lingkup yang terkait dengan proses produksi, pengemasan, penyimpanan dan atau pengangkutan pangan IRT. Persyaratan 
"harus" merupakan persyaratan yang mengindikasikan bila tidak dipenuhi akan mempengaruhi keamanan produk secara langsung dan atau merupakan persyaratan yang wajib dipenuhi, dan dalam inspeksi dinyatakan sebagai ketidaksesuaian kritis. Persyaratan "seharusnya" adalah persyaratan yang mengindikasikan apabila tidak dipenuhi mempunyai potensi mempengaruhi keamanan produk, dan dalam inspeksi dinyatakan sebagai ketidaksesuaian yang serius. Persyaratan "sebaiknya" adalah persyaratan yang mengindikasikan apabila tidak dipenuhi mempunyai potensi mempengaruhi efisiensi pengendalian keamanan produk, dan dalam inspeksi dinyatakan sebagai ketidaksesuaian mayor. Sedangkan persyaratan "dapat" adalah persyaratan yang mengindikasikan apabila tidak dipenuhi mempunyai potensi mempengaruhi mutu (wholesomeness) produk, dan dalam inspeksi dinyatakan sebagai ketidaksesuaian minor.

Setelah dilakukan kajian mendalam, penerapan CPPB-IRT di CV Taruna Bogor berada pada level 4 (empat). Penilaian tersebut didasarkan pada jumlah ketidaksesuaian yang ditemukan, yaitu : 1) Serius sebanyak 3 elemen, yaitu pada lantai, dinding, dan jendela yang kurang terawat, berdebu, dan berlendir; ventilasi, pintu, dan jendela kurang terawat, kotor, tidak memakai kasa, terdapat sarang laba-laba dan penuh debu; peralatan tidak dipelihara dan dalam keadaan kotor, dan tidak menjamin efektivitasnya, 2) Ketidaksesuaian Kritis sebanyak 2 elemen, yaitu tidak tersedia tempat pembuangan sampah tertutup; bahan pangan dan bahan pengemas yang disimpan bersama-sama dengan produk akhir dalam satu ruangan penyimpanan yang bersih, kering dan terang, tetapi diletakkan begitu saja di lantai tanpa menggunakan palet atau alas khusus sehingga produk mi glosor tidak langsung menempel ke lantai. Dapat disimpulkan bahwa CV Taruna memiliki 5 elemen ketidaksesuaian kriteria CPPB-IRT dari 37 elemen ketidaksesuaian. Untuk itu diberikan saran perbaikan untuk memperbaiki penerapan CPPB di CV Taruna sebagaimana disajikan pada Tabel 1 berikut ini.

Tabel 1. Saran Perbaikan penerapan CPPB-IRT di CV Taruna Bogor.

\begin{tabular}{|c|l|l|}
\hline No. & \multicolumn{1}{|c|}{ Elemen CPPB } & \multicolumn{1}{|c|}{ Saran Perbaikan } \\
\hline 1. & $\begin{array}{l}\text { Lantai, dinding dan langit-langit } \\
\text { yang tidak terawat, kotor, berdebu, } \\
\text { terdapat sarang laba-laba dan atau } \\
\text { berlendir }\end{array}$ & $\begin{array}{l}\text { Melakukan perawatan lantai dan dinding } \\
\text { secara berkala, memperbaiki langit-langit } \\
\text { sehingga terhindar dari debu dan sarang } \\
\text { laba-laba serta lantai tidak licin tidak dan } \\
\text { berlendir }\end{array}$ \\
\hline 2. & $\begin{array}{l}\text { Ventilasi, pintu dan jendela yang } \\
\text { kurang terawat, kotor, dan berdebu }\end{array}$ & $\begin{array}{l}\text { Merawat ventilasi, pintu dan jendela } \\
\text { sampai bersih dan terhindar dari kotoran } \\
\text { dan debu }\end{array}$ \\
\hline 3. & $\begin{array}{l}\text { Peralatan produksi yang kurang } \\
\text { terpelihara dan kurang perawatan } \\
\text { serta tidak menjamin efektifnya } \\
\text { penerapan sanitasi }\end{array}$ & $\begin{array}{l}\text { Peralatan produksi dipelihara dan } \\
\text { dirawat dan sehingga dapat menjamin } \\
\text { efektifnya penerapan sanitasi. }\end{array}$ \\
\hline 4. & $\begin{array}{l}\text { Tidak tersedia tempat pembuangan } \\
\text { sampah yang tertutup rapi }\end{array}$ & $\begin{array}{l}\text { Menyediakan tempat pembuangan } \\
\text { sampah yang tertutup }\end{array}$ \\
\hline 5. & $\begin{array}{l}\text { Bahan pangan, bahan pengemas } \\
\text { disimpan bersama-sama dengan } \\
\text { produk akhir dalam satu ruangan } \\
\text { penyimpanan yang kering dan } \\
\text { diletakkan di lantai tanpa alas serta } \\
\text { menempel ke dinding }\end{array}$ & $\begin{array}{l}\text { Bahan pangan, bahan pengemas disimpan } \\
\text { terpisah dengan produk akhir. Ruangan } \\
\text { penyimpan harus bersih, kering dan tidak } \\
\text { diletakkan di lantai dan tidak pula } \\
\text { menempel ke dinding }\end{array}$ \\
\hline
\end{tabular}




\section{Penerapan HACCP di CV Taruna Bogor}

Kajian penerapan HACCP di CV Taruna Bogor yang memproduksi mi glosor dilakukan dengan mengkaji fakta lapangan dan membandingkannya dengan acuan HACCP SNI 01-4852-1998 yang dikeluarkan oleh Badan Standarisasi Nasional (BSN) tentang Sistem Analisa Bahaya dan Pengendalian Titik Kritis (HACCP) serta pedoman penerapannya. Maksud dari kajian ini agar CV Taruna dapat membuat suatu sistem manajemen pengawasan dan pengendalian keamanan pangan produk mi glosor yang dihasilkan. Penerapan HACCP ini bersifat preventif, ilmiah, rasional dan sistematis dengan tujuan untuk mengidentifikasi, memonitor dan mengendalikan bahaya (hazard) mulai dari penyiapan bahan baku, selama proses produksi dan pengolahan, penyimpanan dan penanganan produk akhir serta pemasaran produknya.

Penerapan sistem HACCP di CV Taruna mengikuti tahapan sesuai langkah-langkah penerapan HACCP yaitu dimulai dari pembentukan tim HACCP, mendeskripsikan produk, mengidentifikasi tujuan penggunaan, menyusun diagram alir, memverifikasi diagram alir, menganalisa bahaya, menentukan titik kendali kritis, menetapkan batas kritis, menetapkan prosedur pemantauan, menetapkan tindakan perbaikan. Penerapan langkah dan prinsip HACCP pada CV Taruna ini digunakan untuk mendapatkan daftar tindakan pencegahan yang akan diterapkan pada setiap titik kendali kritis.

CV Taruna memiliki 13 orang karyawan. Pada tahap awal pembentuk-an tim dilakukan pembinaan dan pemberian pengetahuan dasar dan keterampilan dasar tentang mutu, keamanan pangan dan cara produksi pangan olahan yang baik dan benar. Minimnya pendidikan para pekerja memerlukan pendekatan tersendiri dalam pengajaran dengan memodifikasi pengajaran menjadi pengajaran yang sederhana dengan bahasa populer yang mudah diterima oleh peserta yang berpendidikan rendah. Pembelajaran dan pembentukan tim HACCP memfokuskan pada keterampilan teknis penerapan aktivitas kritis yang praktis. Penilaian pemahaman setiap anggota tim dilakukan dengan pengamatan dan pemeriksaan hasil kerja. Keterampilan diperoleh dengan mengerjakan pekerja-an secara berulang-ulang sehingga para peserta memahami dan terampil menerapkan CPPB yang menjadi prasyarat penerapan sistem HACCP.

Gambar 3. Struktur personalia di CV Taruna Bogor.

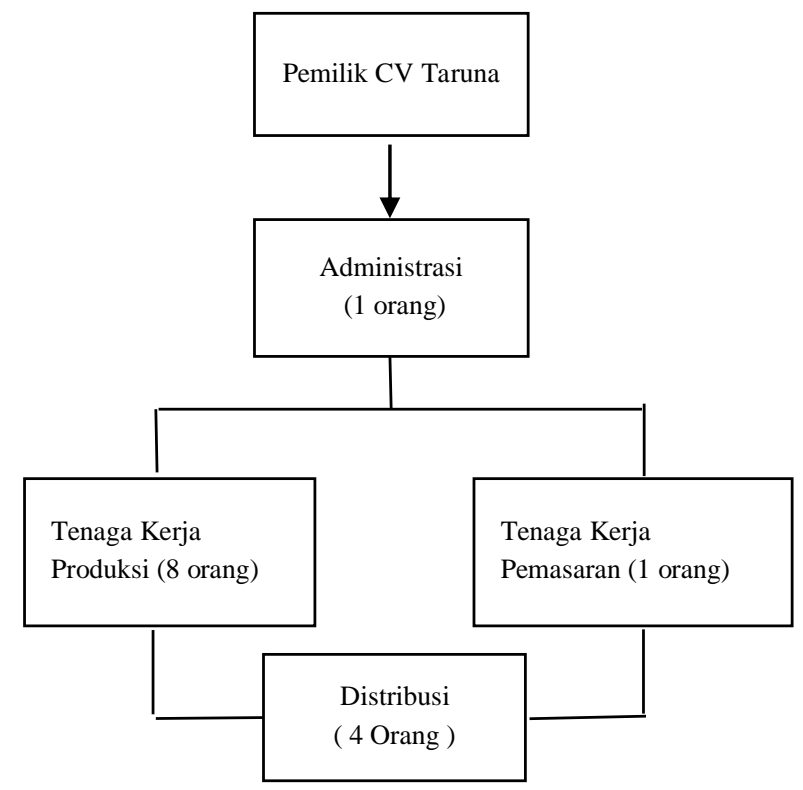

Tim HACCP di CV Taruna dibentuk secara mandiri dengan pemilik pabrik sebagai ketua tim dan beranggotakan para karyawan pabrik sebagaimana strukturnya dapat dilihat pada Gambar 2 berikut. Agar penerapan sistem berjalan dengan baik, maka perlu diawali dengan komitmen dari pemilik pabrik sebagai penanggung jawab mutu dan keamanan produk yang dihasilkan. Kemudian pemilik pabrik memberikan instruksi dan tata kerja penerapan sistem mutu dan keamanan pangan. Pemberian ilmu tersebut dapat dilakukan dengan beberapa cara yaitu dengan cara memberikan contoh langsung, ataupun memberikan arahan baik itu berupa pengarahan sebelum pekerjaan dimulai, ataupun pada saat evaluasi setelah selesai produksi. Transfer pengetahuan dan keterampilan dari pemilik pabrik kepada para pegawai dilakukan dengan pengajaran singkat, pemberian contoh, pengawasan dan evaluasi penerapan HACPP secara berkala. 
Pada tahapan penerapan sistem HACPP dilakukan dengan meng-identifikasi tujuan penggunaan sistem HACCP, penyusunan diagram alir proses produksi, memverifikasi diagram alir dan menganalisa bahaya yang mungkin timbul serta menentukan titik kendali kritisnya dan diakhiri dengan menetap-kan prosedur pemantauan dan menetapkan tindakan perbaikan jika terjadi potensi bahaya.

Penerapan HACCP di CV Taruna dimulai dengan proses pengayakan bahan baku berupa tepung sagu aren untuk menghilangkan bahaya fisik berupa kontaminasi benda asing seperti rambut, kawat, kerikil, debu dan tanah. Para pekerja harus mencegah adanya bahaya kimia yaitu terkontaminasi bahan kimia berbahaya pada tepung baik sebelum maupun setelah diayak serta selama proses pengolahan pembuatan mi glosor. Selain bahaya fisik dan kimia, para pekerja juga harus mencegah masuknya bahaya biologi berupa bakteri, jamur, kutu dan mikro-organisme patogen lainnya. Tindakan yang dilakukan untuk mencegah cemaran biologi adalah dengan mencuci tangan setiap akan mulai bekerja, membersihkan peralatan sebelum dan setelah dipakai, menjaga kebersihan diri pekerja, serta menjaga kebersihan lingkungan kerja di CV Taruna dan mencegah munculnya serangga seperti semut dan kecoa maupun binatang pengerat seperti tikus.

Air merupakan bahan penolong proses utama yang digunakan untuk pembuatan mi glosor. Sumber air di CV Taruna menggunakan air sumur yang yang ditampung di dalam toren penampung air. Pengujian secara berkala kebersihan air dilakukan di Balai Besar Industri Agro (BBIA) Bogor. Air digunakan dalam pembuatan adonan, merendam mie setelah dicetak, serta mencuci mie yang telah diproduksi.

\section{Penetapan CCP}

Penetapan CCP di CV Taruna merupa-kan tahap awal untuk mengidentifikasi aktivitas kritis yang memungkinkan timbulnya bahaya pada tiap tahapan proses pembuatan mi glosor. Pada proses produksi mi glosor terdapat 8 (delapan) titik kritis yang memerlukan pengendalian sebagaimana dapat dilihat pada Gambar 4 .

Setelah dilakukan analisa titik kritis bahaya pada tiap tahapan mi glosor, kemudian dilanjutkan dengan penetapan batas kritis dari tiap titik kritis, metode dan frekuensi monitoring serta tindakan koreksi yang harus dilakukan jika terjadi ketidaksesuaian. Tindakan koreksi pada tiap tahapan kritis pembuatan mi glosor di CV Taruna dapat dilihat pada Tabel 2 . 
Gambar 4. Titik kritis yang memerlukan pengendalian pada pembuatan mi glosor di CV Taruna Bogor.

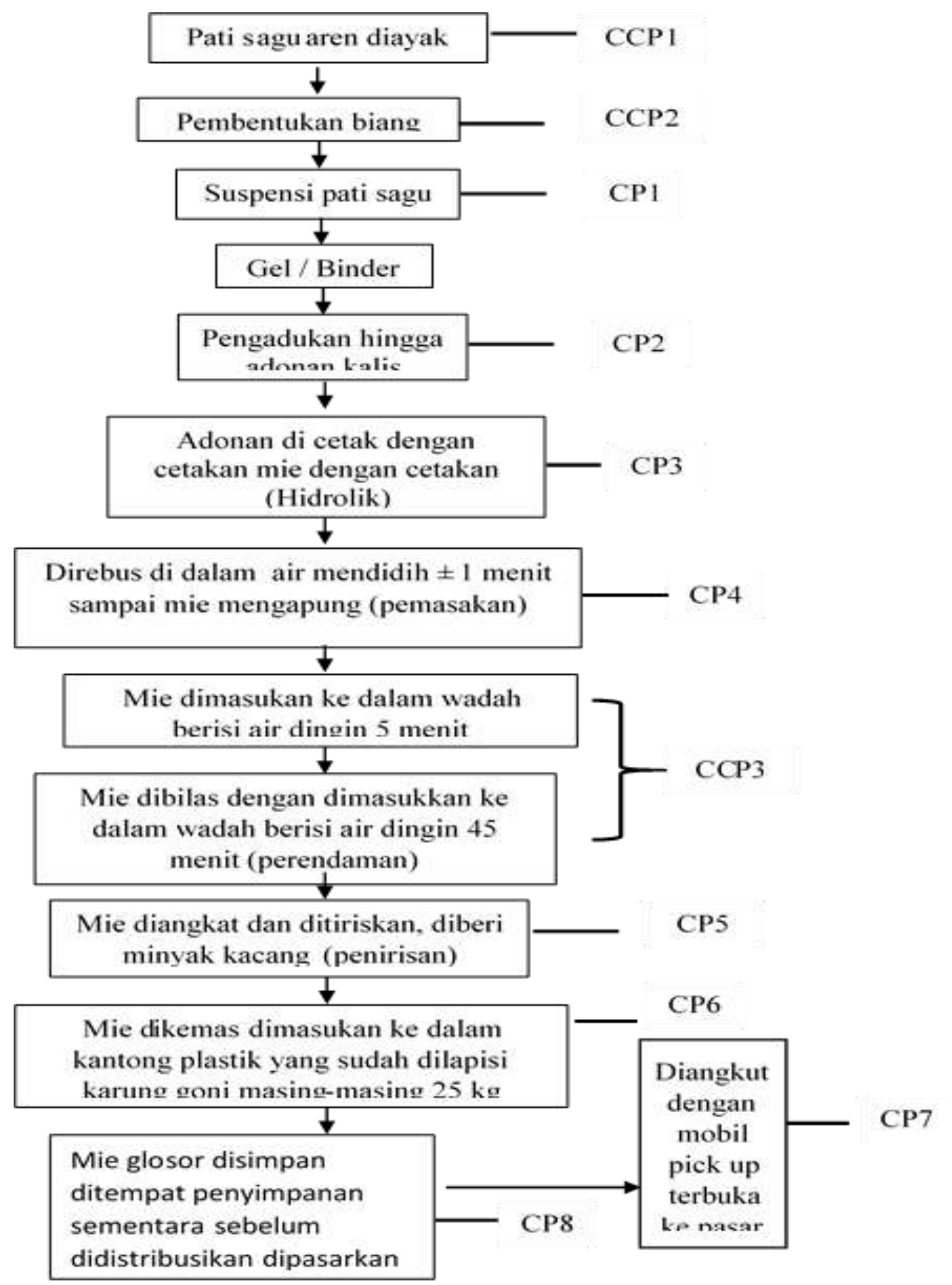


Tabel 2. Tindakan Koreksi Proses Pembuatan Mi Glosor di CV Taruna Bogor

\begin{tabular}{|c|c|c|c|c|c|c|}
\hline \multirow[t]{2}{*}{ Tahap } & \multirow[b]{2}{*}{ ССР } & \multirow{2}{*}{$\begin{array}{l}\text { Jenis } \\
\text { Bahaya }\end{array}$} & \multirow[t]{2}{*}{ Batas Kritis } & \multicolumn{2}{|c|}{ Monitoring } & \multirow{2}{*}{$\begin{array}{l}\text { Tindakan } \\
\text { Koreksi }\end{array}$} \\
\hline & & & & Metode & Frekuensi & \\
\hline Pengayakan & 1 & Fisika & $\begin{array}{l}\text { Peralatan yang } \\
\text { digunakan bersih, } \\
\text { sanitasi lingkungan }\end{array}$ & $\begin{array}{l}\text { Cek alat untuk } \\
\text { mengayak, } \\
\text { kebersihan } \\
\text { karyawan serta } \\
\text { lingkungan }\end{array}$ & $\begin{array}{l}\text { Setiap } \\
\text { produksi }\end{array}$ & $\begin{array}{l}\text { Monitoring } \\
\text { sehingga } \\
\text { aman dari } \\
\text { bahaya fisik }\end{array}$ \\
\hline \multirow{2}{*}{$\begin{array}{l}\text { Pengadonan } \\
\text { dan } \\
\text { pembentukan } \\
\text { biang } \\
\end{array}$} & 2 & Biologi & $\begin{array}{l}\text { Peralatan yang } \\
\text { digunakan bersih, } \\
\text { sanitasi lingkungan }\end{array}$ & $\begin{array}{l}\text { Pastikan } \\
\text { peralatan bersih }\end{array}$ & $\begin{array}{l}\text { Setiap } \\
\text { produksi }\end{array}$ & monitoring \\
\hline & 2 & kimia & $\begin{array}{l}\text { penambahan } \\
\text { pewarna }\end{array}$ & $\begin{array}{l}\text { Pastikan } \\
\text { pemberian } \\
\text { pewarna sesuai } \\
\text { keperluan }\end{array}$ & $\begin{array}{l}\text { Setiap } \\
\text { produksi }\end{array}$ & $\begin{array}{l}\text { Monitoring } \\
\text { pemberian } \\
\text { pewarna } \\
\text { sesuai } \\
\text { kebutuhan } \\
200 \mathrm{mg} / \mathrm{kg}\end{array}$ \\
\hline Pencetakan & 3 & biologi & $\begin{array}{l}\text { Peralatan yang } \\
\text { digunakan bersih, } \\
\text { sanitasi lingkungan }\end{array}$ & $\begin{array}{l}\text { Pastikan } \\
\text { peralatan bersih }\end{array}$ & $\begin{array}{l}\text { Setiap } \\
\text { produksi }\end{array}$ & $\begin{array}{l}\text { Memonitor } \\
\text { alat cetak } \\
\text { harus bersih }\end{array}$ \\
\hline Perebusan & 4 & biologi & $\begin{array}{l}\text { Sumber air yang } \\
\text { digunakan } \\
\text { bersih,bebas } \\
\text { mikroba dan } \\
\text { kontaminan logam } \\
\text { serta bebas dari } \\
\text { berbagai benda }\end{array}$ & $\begin{array}{l}\text { Ganti air dengan } \\
\text { air yang benar } \\
\text { benar bersih }\end{array}$ & $\begin{array}{l}\text { Setiap } \\
\text { produksi }\end{array}$ & $\begin{array}{l}\text { Memonitor } \\
\text { suhu } \\
\text { perebusan }\end{array}$ \\
\hline Perendaman & 5 & Biologi & $\begin{array}{l}\text { Sumber air yang } \\
\text { digunakan } \\
\text { bersih,bebas } \\
\text { mikroba dan } \\
\text { kontaminan logam } \\
\text { serta bebas dari } \\
\text { berbagai benda }\end{array}$ & $\begin{array}{l}\text { Jaga kebersihan } \\
\text { air , karyawan } \\
\text { dan lingkungan }\end{array}$ & $\begin{array}{l}\text { Setiap } \\
\text { produksi }\end{array}$ & $\begin{array}{l}\text { Monitoring } \\
\text { penggunaan } \\
\text { air yg } \\
\text { berkualitas }\end{array}$ \\
\hline Penirisan & 6 & $\begin{array}{l}\text { Fisika } \\
\text { Biologi }\end{array}$ & $\begin{array}{l}\text { Peralatan yang } \\
\text { digunakan bersih, } \\
\text { sanitasi lingkungan } \\
\text { Pemberian minyak } \\
\text { kacang yang } \\
\text { bermutu }\end{array}$ & $\begin{array}{l}\text { Pastikan } \\
\text { peralatan yang } \\
\text { digunakan } \\
\text { bersih. } \\
\text { Pastikan minyak } \\
\text { kacang yg } \\
\text { digunakan dalam } \\
\text { keadaan baik. }\end{array}$ & $\begin{array}{l}\text { Setiap } \\
\text { produksi }\end{array}$ & $\begin{array}{l}\text { Melihat } \\
\text { secara visual } \\
\text { kebersihan } \\
\text { alat } \\
\text { penirisan. } \\
\text { Melihat } \\
\text { kebersihan, } \\
\text { warna dan } \\
\text { aroma } \\
\text { minyak } \\
\text { kacang } \\
\text { sebelum } \\
\text { ditambahkan } \\
\text { ke mi glosor }\end{array}$ \\
\hline Pengemasan & 7 & Biologi & $\begin{array}{l}\text { Kemasan harus } \\
\text { bersih, dan } \\
\text { perhatikan } \\
\text { kebersihan } \\
\text { lingkungan produksi }\end{array}$ & $\begin{array}{l}\text { Pastikan } \\
\text { kemasan yg } \\
\text { digunakan bener } \\
\text { bener bersih }\end{array}$ & $\begin{array}{l}\text { Setiap } \\
\text { produksi }\end{array}$ & $\begin{array}{l}\text { Memonitor } \\
\text { kemasan } \\
\text { yang } \\
\text { digunakan } \\
\text { bersih } \\
\end{array}$ \\
\hline Penyimpanan & 8 & biologi & $\begin{array}{l}\text { Produk tidak } \\
\text { langsung } \\
\text { bersentuhan dengan }\end{array}$ & $\begin{array}{l}\text { Cek kondisi } \\
\text { tempat } \\
\text { penyimpanan }\end{array}$ & $\begin{array}{l}\text { Setiap } \\
\text { produksi }\end{array}$ & $\begin{array}{l}\text { Memonitor } \\
\text { gudang } \\
\text { penyimpan }\end{array}$ \\
\hline
\end{tabular}




\begin{tabular}{|l|l|l|l|l|l|l|}
\hline & & & $\begin{array}{l}\text { lantai dan dinding. } \\
\text { Gunakan palet. } \\
\text { Gudang tidak lembab. } \\
\text { Terhindar dari bahan } \\
\text { kimia berbahaya }\end{array}$ & & & $\begin{array}{l}\text { senantiasa } \\
\text { bersih dan } \\
\text { rapih }\end{array}$ \\
\hline Pengangkutan & 8 & Biologi & $\begin{array}{l}\text { Alat pengangkutan } \\
\text { bersih dan kering. } \\
\text { Bak mobil diberi alas } \\
\text { yang bersih. }\end{array}$ & $\begin{array}{l}\text { Cek kebersihan } \\
\text { mobil angkutan }\end{array}$ & $\begin{array}{l}\text { Setiap } \\
\text { produksi }\end{array}$ & $\begin{array}{l}\text { Memonitor } \\
\text { bak angkutan } \\
\text { senantiasa } \\
\text { bersih }\end{array}$ \\
\hline
\end{tabular}

\section{Dokumentasi dan Rekaman Penerapan HACCP}

Tahap akhir dari implementasi sistem HACCP di CV Taruna yang merupakan industri kecil adalah dengan pembuatan dokumentasi dan rekaman penerapan HACCP. Dokumentasi yang baik dapat membantu memudahkan dalam memantau apakah penerapan sistem HACCP telah dilaksanakan dengan baik atau tidaknya. Tantangan penerapan sistem dokumentasi dan rekaman pada usaha kecil pertama kali adalah mengubah budaya organisasi yang mengandalkan kebiasaan saja tanpa pencatatan menjadi terbiasa mencatat. Setiap perubahan budaya akan mendapat tantangan dari orang-orang yang sudah merasa nyaman dengan kebiasaan yang sudah selama ini dijalankan. Agar penerapan sistem HACCP ini dapat dijalankan maka langkah awal penerapan sistem ini dilakukan dengan adanya komitmen dari pemilik perusahaan yang memiliki pengaruh besar di pembuatan mi glosor ini. Langkah selanjutnya adalah dengan memperkenalkan sistem HACCP dengan cara yang sederhana kepada para pekerja dengan memberikan contoh dan keteladanan dalam penerapannya. Kemudian setelah sistem ini dimulai perlu ada monitoring dan pembiasaan di semua tim yang terlibat. Form-form yang dibuat haruslah sesederhana mungkin, setiap tim merasa aktivitas ini mudah dikerjakan, dan menjadi kebiasaan setiap tim yang bertugas. Pencatatan yang baik akan memudahkan dalam penelusuran produk yang dimulai dari pencatatan barang datang, catatan penimbangan, catatan produk akhir dan catatan penjualan yang lengkap dengan penanggung jawab dan jadwal/waktu pengerjaannya.
Dengan adanya pendokumentasian yang baik diharapkan penerapan, pengevaluasian dan perbaikan penerapan sistem HACCP di CV Taruna dapat dilakukan dengan baik.

\section{KESIMPULAN}

Implementasi penerapan HACCP di industri kecil mi glosor di CV Taruna Bogor diawali dengan evaluasi penerapan Cara Produksi Pangan Olahan yang Baik (CPPB) yang menjadi prasyarat dalam penerapan sistem HACCP di pabrik pengolahan pangan. Penerapan CPPB IRT di CV Taruna ini berada pada level 4 (empat) yang didasarkan pada jumlah ketidaksesuaian yang ditemukan, yaitu ketidaksesuaian Serius sebanyak 3 elemen dan ketidaksesuaian Kritis sebanyak 2 elemen. Setelah melakukan tindakan perbaikan dalam penerapan CPPB dilanjutkan dengan identifikasi penetap-an bahaya yang perlu dikendalikan dalam setiap tahapan proses produksi mi glosor. Pada tahap ini ditemukan 8 titik kendali kritis yang perlu dibuat batas kritis, monitoring dan tindakan perbaikan yang perlu dilakukan untuk mengantisipasi bahaya yang mungkin timbul. Pada tahap akhir penerapan HACCP di CV Taruna Bogor dibuat sistem dokumentasinya agar penerapan sistem dapat dimonitor, dievaluasi, dan dilakukan tindakan perbaikan untuk memperbaiki penerapan sistem yang telah dijalankan.

\section{DAFTAR PUSTAKA}

Astawan, M. 2009. Membuat Mie dan Bihun. Jakarta: Penebar Swadaya.

Buckle, K.A., Edwards, R.A., Fleet, G.H. and Wootton, M. 2013. Ilmu Pangan. Terjemahan dari Food Science oleh 
Purnomo, H. dan Adiono. Penerbit Universitas Indonesia (UI Press), Jakarta.

Bedi, J. S. 2006. Cross-validation of production and consumption data of fruits and vegetables. Economic and Political Journal 30(1) : 45-53

[BSN] Badan Standardisasi Nasional. 1998. Standar Nasional Indonesia - SNI 48521988. Sistem Analisa Bahaya dan Pengendalian Titik Kritis (Hazard Analysis Critical Control Point-HACCP) serta Pedoman Penerapannya. Jakarta (ID): Badan Standardisasi Nasional.

[BSN] Badan Standarisasi Nasional Indonesia - No. 1004-1999 tentang Panduan Penyusunan Rencana. Sistem Analisa Bahaya dan Pengendalian titik. KritisHACCP

[BPOM] Badan Pengawasan Obat dan Makanan Republik Indonesia Peraturan Kepala BPOM RI No. HK. 03.123.04.12.2206 Tahun 2012 tentang CPPB di Industri Rumah Tangga.

Cahyono. B. 2009. Food Safety dan Implementasi Quality System Industri Pangan di Era Pasar Bebas, Biro Humas, Persidangan, dan Administrasi Pimpinan, Kantor Menteri Negara Perencanaan Pembangunan Nasional (BAPPENAS).

Deswanti, Ratih. 2013. HACCP (Hazard Analysis Critical Control Point.) Pendekatan Sistematik Pengendalian Keamanan Pangan. PT Dian Rakyat, Jakarta.

Feigenbaum. 1996. Kendali Mutu Terpadu. Terjemahan Hudaya Kandahjaya. Erlangga.
Hariyadi, Purwiyatno. 2008. Isu Terkini Terkait dengan Keamanan Pangan. Jurnal dalam Pra-Widyakarya Nasional Pangan dan Gizi IX. 9 Juni 2008.

Kementrian Perindustrian RI. 2010. Peraturan Menteri Perindustrian Republik Indonesia Tentang Pedoman Cara Produksi Pangan Olahan yang Baik (Cara Produksi Pangan yang Baik). Nomor: 75/M-IND/PER/7/2012.

Kemdiknas. 2011. Keamanan Makanan Jajanan. Pustekkom Kemdiknas.

Mortimore, S., C. Wallace. 2005. HACCP Sekilas Pandang (Diterjemahkan oleh

Apriningsih SKM). Jakarta: EGC

Miskiyah, Widaningrum, dan Hetty Herawati. 2006. Studi Penerapan HACCP, Jurnal Standardisasi Vol. 8 No. 1, Maret 2006: 27-34

Sukmawati, 2015. Kesesuaian penerapan manajemen mutu ikan pindang bandeng (Chanos chanos) Terhadap Standar Nasional Indonesia. Jurnal Manajemen IKM 10 (2): 163- 172

Purwani, E.Y., Widaningrum, Thahir, R. dan Muslish. 2006. Effect of Heat Moisture Treatment of Sagu Starch on its Noodle Quality. Indonesian Journal of Agricultural Science 7(1): 8-14.

Thaheer, H. 2005. Sistem Manajemen HACCP (Hazard Analysis and Critical Control Points). PT. Bumi Aksara, Jakarta.

Winarno, FG dan Surono. 2011. GMP Cara Pengolahan Pangan Yang Baik. Bogor: M-BRIO PRESS, Cetakan ke-2. 